\title{
Decline in commercial pine nut and kernel yield in Mediterranean stone pine (Pinus pinea L.) in Spain
}

\author{
Rafael Calama ${ }^{(1-2)}$, \\ Javier Gordo ${ }^{(3)}$, \\ Sven Mutke ${ }^{(1-2)}$, \\ Mar Conde ${ }^{(1)}$, \\ Guillermo Madrigal ${ }^{(1-2)}$, \\ Enrique Garriga ${ }^{(4)}$, \\ María José Arias ${ }^{(5)}$, \\ Míriam Piqué ${ }^{(6)}$, \\ Rodrigo Gandía ${ }^{(7)}$, \\ Gregorio Montero ${ }^{(1-2)}$, \\ Marta Pardos ${ }^{(1-2)}$
}

\begin{abstract}
Cones of the Mediterranean stone pine (Pinus pinea L.) constitute one of the most relevant non-wood forest products collected in the Mediterranean forests, providing high value edible kernels. In the last years it has been observed a severe decline in the kernel-per-cone yield (kg of kernels obtained from a $\mathrm{kg}$ of fresh cones) through the whole area of the species. This decline has been associated with both ongoing climate change and the recent expansion over the Mediterranean Basin of the Western Conifer Seed Bug, Leptoglossus occidentalis Heideman, an exotic pest which predates seeds of conifer species. In the present work we aimed to confirm and quantify the impact of this recent decline on pine nut and kernel production, identify the main factors provoking this reduction, and give evidence over causality by a potential biotic agent. We analysed recent and historical series of pine nut and kernel production obtained in the four main regions where Pinus pinea occurs in Spain. Our results showed a significant drop in the final kernel-per-cone yield on three of the four regions analysed, reaching reductions over $50 \%$ in the most affected areas. We observed that this reduction is mainly associated with a significant and generalised drop in the kernel-per-nut yield (kg of kernels per $\mathrm{kg}$ of pine nuts in shell), triggered by an increment in the rate of damaged pine nuts and, to a lesser extent, a reduction in the number of pine nuts per cone. The prevalence of this reduction on kernel-per-cone yield over different years and provenances with contrasting climate reinforces the hypothesis of the implication of a biotic factor which can be aggravated on extreme drought years.
\end{abstract}

Keywords: Leptoglossus occidentalis, Kernel-per-Cone Yield, Cones, Exotic Pest, Seed Predation

\section{Introduction}

Cones of the Mediterranean stone pine (Pinus pinea L.) constitute one of the most important non-wood forest products collected in the Mediterranean Basin. Each cone renders up to $100-120$ seeds, called "pine nuts", whose small edible, ivorywhite kernels, have been appreciated for their flavour since ancient times. In addition, they have excellent dietetic values with high content in proteins (35\%) and minerals (phosphorus, iron, zinc, magnesium) but a low content in saturated fatty acids (Evaristo et al. 2010, Salas-Salvadó et al. 2011). The Mediterranean pine nut, as one of the most important wild edible nuts collected in the world, is mainly produced in Spain, Portugal, Turkey and Italy (INC 2012). Cones are collected when they are still closed, during fall and winter seasons. Once in the industry, collected cones can be processed immediately by boiling into water to open or can be stored outdoors or sheltered in the factory and air dried up until cone dehiscence, which takes place in May-June. The subsequent industrial process includes cone opening, separation of woody parts from the pine nuts which are still in shell, storage and final shelling of pine nuts to obtain the kernels. Cones yield in weight corresponds to $15-20 \%$ seeds and only $3-4 \%$ kernels, giving $1 \mathrm{~kg}$ of kernels per
25-30 kg of fresh cones, varying widely between years and regions (Gordo et al. 1999, Montero et al. 2004).

This low percentage of edible kernels together with the limited supply associated with wild-collected food, might explain the high retail prices for kernels, exceeding 60$70 € \mathrm{~kg}^{-1}$. Due to the high price paid, many stone pine forest owners have orientated the management of the species towards optimizing cone rather than timber production (Pasalodos-Tato et al. 2016), backed up by an extensive scientific knowledge on optimal management (Freire et al. 2016), tree breeding (Mutke et al. 2005) and domestication based on agronomy techniques (Guadaño et al. 2016).

Several sources of uncertainty condition the commercial and industrial process of cone transformation. The first is the lack of sustained cone supply from forests, linked to the large interannual variability in cone production, this variability reaching more than 100-fold in interior Spain (Calama et al. 2016a). The masting habit of the species is largely triggered by climate events (mainly rainfall during key phases of cone development) affecting strobilus induction in the year prior to female flower emertion (Mutke et al. 2005, Calama et al. 2016a). Drought or extreme winter frosts gence, i.e., three years before cone collec- 
during the three-year process of cone development can cause conelet losses, reducing the final crop of cones. In addition, resource depletion during a bumper crop inhibits the induction of the next female conelet cohort (Mutke et al. 2005).

A second source of uncertainty is the potential effect of cone pests. Two native insects are the main agents of biotic damage in immature $P$. pinea cones throughout the distribution area of the species (Bracalini et al. 2013): the pine cone moth Dioryctria mendacella Stgr. and the weevil Pissodes validirostris Gyll. Larvae of both species mine feeding galleries in the cones, destroying their commercial value, with recent studies pointing to a major incidence of D. mendacella that can affect $20-30 \%$ of the total annual cone production (Calama et al. 2017a).

The last issue of concern is related with pine nut yield in cones. The raw material entering the cone processing industry are the fresh closed green cones. Industry processors aim to obtain the largest "kernelper-cone" yield, defined as $\mathrm{kg}$ of kernels obtained per kg of fresh cones. This kernelper-cone yield is the product of two intermediate yields, the "nuts-per-cone yield", defined as $\mathrm{kg}$ of shelled pine nuts obtained from a kg of fresh cones, and the "kernelper-nut yield" defined as kg of kernels obtained per kg of pine nuts.

The nuts-per-cone yield is largely linked to parameters such as the average number of pine nuts per cone or per $\mathrm{kg}$ of fresh cones and mean size (weight) of pine nuts (Morales 2009). These parameters are positively correlated with the average weight of a single cone (Mutke et al. 2007), which can roughly vary between $100-500 \mathrm{~g}$ and is largely controlled by the rainfall amount during the last year of cone maturation

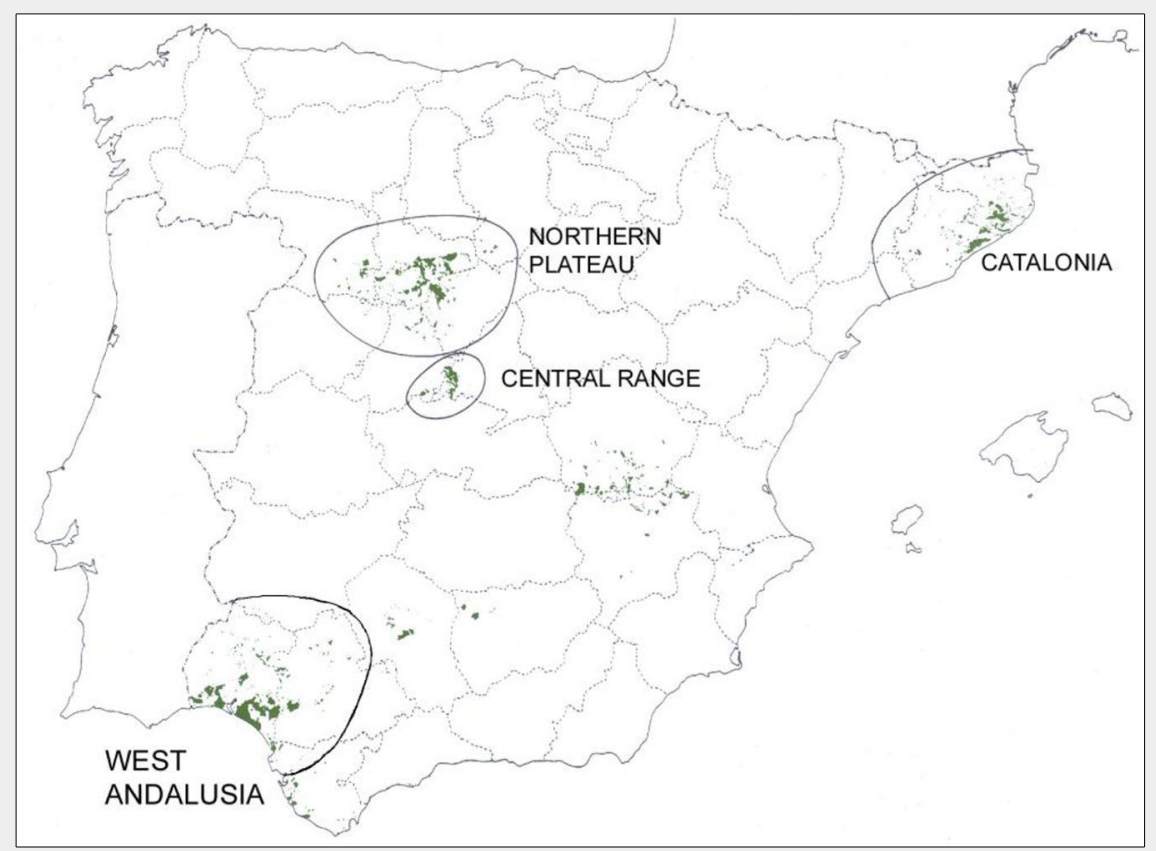

Fig. 1 - The four studied regions in Spain.

(Mutke et al. 2007, Guadaño et al. 2016, Loewe-Muñoz et al. 2019). As a consequence, nuts-per-cone yield has historically shown large between-year variability, ranging from 0.08 to 0.20 , associated with annual climate conditions.

As regards kernel-per-nut yield, up to 2010 it was relatively constant, with values ranging from 0.20-0.24. Interannual variability was mainly associated with the rate of damaged or empty pine nuts which accounted for $10 \%-20 \%$ of the pine nuts of the cone (Montero et al. 2004, Morales 2009). This rate of empty pine nuts is also negatively correlated with the average cone weight and was found to be higher after dry springs with smaller cones (Mutke et al. 2007, Morales 2009).

Since 2012, the alarm has been raised by forest owners, cone pickers and processing industries, that production had dropped off drastically in all cone-producing countries (Sousa et al. 2012, Bracalini et al. 2013, Ozçankaya et al. 2013, Calama et al. 2015). In the field, cone pickers have reported a dramatically high number of dry unripe conelets in their first and second year of development, and processing industries have observed a significant drop in kernelper-cone yield, derived from percentages of damaged pine nuts (empty or containing only withered remains of the kernel) of over 50\% (Mutke et al. 2017). The rapid, coincident and generalised increase in both phenomena, aborted conelets and damaged seeds, has given rise to the term "Dry Cone Syndrome" (DCS), suggesting a possible common agent (Tiberi 2007). However, despite the economic incidence of DCS, very few data from forests and factories have been published that allow the quantification of its incidence (Mutke et al. 2017). 
Tab. 1 - Cone, nut and kernel variables and ratios.

\begin{tabular}{|c|c|c|c|c|}
\hline Variable & Unit & Name & Formula & Description \\
\hline SFW & g & Fresh weight of the set of cones & - & varies with water content $(\mathrm{H} \%)$ \\
\hline $\mathrm{SCN}$ & - & Number of cones in the set & - & up to 5 cones \\
\hline CFW & g & Cone fresh weight & $\mathrm{CFW}=\mathrm{SFW} / \mathrm{SCN}$ & Mean weight of one cone \\
\hline SDW & g & Set dry weight & - & oven-dried $\left(1\right.$ week, $\left.45{ }^{\circ} \mathrm{C}\right)$ \\
\hline CDW & g & Cone dry weight & $\mathrm{CDW}=\mathrm{SDW} / \mathrm{SCN}$ & mean dry weight of one cone \\
\hline $\mathrm{H} \%$ & $\%$ & Relative Humidity & $H \%=1-(S D W / S F W)$ & decreases with harvest date \\
\hline CFW* $^{*}$ & $\mathrm{~g}$ & Standardized cone fresh weight & $\mathrm{CFW}^{*}=\mathrm{CDW} / 63 \%$ & mean cone weight at $37 \%$ humidity (November harvest) \\
\hline NPS & - & Number of pine nuts in the set & - & excl. aborted seeds $(<4 \mathrm{~mm})$ \\
\hline NPC & - & Number of pine nuts per cone & $N P C=N P S / S C N$ & - \\
\hline NP_kg & $\mathrm{kg}^{-1}$ & Number of pine nuts per $\mathrm{kg}$ of cones & $N P \_k g=N P C / C F W^{*}$ & - \\
\hline WPS & g & Weight of pine nut sample & - & in shell \\
\hline NP_SS & - & Number of pine nuts in subsample & - & up to 50 pine nuts \\
\hline WP_SS & g & Weight of pine nuts in the subsample & - & - \\
\hline WP & g & Pine nut mean weight in shell & $W P=W P S / N P S$ & Mean weight of one pine nut \\
\hline NK_SS & - & Number of kernels in the subsample & - & excl. empty or damaged seeds \\
\hline D & - & Rate of damaged or empty nuts & 1- (NK_SS / NP_SS) & - \\
\hline WK_SS & g & Weight of kernels from subsample & - & - \\
\hline WK & g & Kernel mean weight & W= WK_SS / NK_SS & Mean weight of one kernel \\
\hline NCY & - & Nut-per-cone yield & $N C Y=N P \_k g \cdot W P$ & weight of inshell pine nuts obtained from one $\mathrm{kg}$ of cones \\
\hline KNY & - & Kernel-per-nut yield & KNY = WK_SS / WP_SS & weight of kernels obtained from one $\mathrm{kg}$ of inshell pine nuts \\
\hline KCY & - & Kernel-per-cone yield & $\mathrm{KCY}=\mathrm{NCY} \cdot \mathrm{KNY}$ & weight of kernels obtained from one $\mathrm{kg}$ of cones \\
\hline
\end{tabular}

nut yield and a larger influence of this component over the final kernel-per-cone yield; (ii) a greater influence of the rate of damaged pine nuts in both kernel-per-nut and kernel-per-cone yields; (iii) a significant and maintained increase in the rate of damaged or empty pine nuts, irrespective of interannual changes in climate conditions and average cone weight.

\section{Materials and methods}

\section{Studied regions}

The studied regions include the four most important provenance regions for the species in Spain (Prada et al. 1997 - Fig. 1): Catalonia, South West Andalusia, Northern Plateau and the Central Range. These four regions differ considerably in terms of ecological conditions and traditional management, as summarised in Tab. S1 (Supplementary material).

\section{Cone collection}

\section{Historical surveys}

Between 1992 and 2000 INIA-CIFOR installed a network of permanent plots in pure even-aged stands of Pinus pinea in the four studied regions. The plots were circular, with variable radius in order to include 20 trees. Plot location aimed to cover the whole range of site quality, stand stocking and age classes identified in each region. Mature cones were collected every autumn from the five trees closest to the centre of the plot, counting and weighing healthy and damaged cones (Dioryctria mendacella and Pissodes validirostris). A subsample of five cones per tree, without signs of damage, were randomly selected and sent to the laboratory for further analysis related to pine nut and kernel yield and quality. While annual cone collection in these experimental plots is still ongoing (e.g., in the case of the Northern Plateau, there is now a temporal series covering more than 20 years of fruit production), nut and kernel extraction was stopped in 2005 due to costs and because the means appeared to be stable. The average number of plots sampled annually in the historical surveys (Tab. S2 in Supplementary material) ranged from 18 (Northern Plateau) to 44 (Central Range).

\section{Recent surveys}

In the 2012-2013 survey, motivated by the generalised distress of the cone processing industry, the INIA-CIFOR, in cooperation with the Forest Service of Valladolid, restarted the studies of nut and kernel yield and quality in the plots on the Northern Plateau. In subsequent years, the studies were extended again to Catalonia, the Central Range and South West Andalusia, where, as in the case of the N. Plateau, the presence of $L$. occidentalis has been confirmed (Fent \& Kment 2011). In the case of the Northern Plateau the new sampling points were coincident with former INIA plots, which were still active. For the other regions, new sampling points were selected, aiming to cover the previously sampled areas and extending the network to new areas within the region. The average number of plots annually sampled in these recent surveys (Tab. S1 in Supplementary material) ranged from 5 (Central Range) to 34 (Northern Plateau). In these new sam- pling plots, cones were annually collected from five trees per plot, and a sample of 15 to 25 randomly selected healthy cones was sent to the laboratory for processing (see below).

\section{Nut and kernel content analysis}

The cones from a given plot and year were randomly separated into three to five sets (Tab. S2 in Supplementary material), including five cones each. Each set of cones was labelled, and its fresh weight was recorded using a scale with a precision of $1 \mathrm{~g}$. Each set of cones was oven-dried at $45^{\circ} \mathrm{C}$ for a minimum period of a week until the cones opened. After complete opening of the cones, the sample was weighed again (Tab. 1).

The pine nuts, still in the shell, were manually extracted from each set. Pine nuts shorter than $4 \mathrm{~mm}$ were considered as aborts and removed. The rest of the pine nuts were counted using an automatic seed counter, and weighed with a precision of $0.1 \mathrm{~g}$. A subsample of 50 pine nuts (or all of them, if the whole sample was smaller) from each set was randomly selected for the analysis of kernel yield and weighed with a precision of $0.1 \mathrm{~g}$. Pine nuts were cracked using a manual nut cracker and classified and counted as sound "Kernels" or as "Damaged" nuts. Similitude of damage with those observed in L. occidentalis experimental cages and feeding assays allowed us to use the damage classification established for the species (Calama et al. 2017b, Farinha et al. 2018a - Fig. S1 in Supplementary material). Sound kernel lots were weighed with a precision of $0.1 \mathrm{~g}$. From the above analysis we were able to 
Tab. 2 - Mean values ( \pm standard error) for kernel-per-cone yield, nut-per-cone yield and kernel-per-nut yield in the four regions in both historical and recent periods. P-value refers to statistical differences between periods for a given region. For the same row, the same lowercase indicates non-significant differences $(p>0.05)$ between regions in the same period.

\begin{tabular}{llllcl}
\hline Yield & Period & Catalonia & SW Andalusia & Northern Plateau & Central Range \\
\hline \multirow{3}{*}{ Kernel-per-cone } & Historical & $0.0236 \pm 0.0006^{\mathrm{c}}$ & $0.0334 \pm 0.0005^{\mathrm{b}}$ & $0.0352 \pm 0.0006^{\mathrm{a}}$ & $0.0349 \pm 0.0004^{\mathrm{a}}$ \\
& Recent & $0.0155 \pm 0.0017^{\mathrm{b}}$ & $0.0321 \pm 0.0020^{\mathrm{a}}$ & $0.0177 \pm 0.0005^{\mathrm{b}}$ & $0.0299 \pm 0.0013^{\mathrm{a}}$ \\
& $p$-value & 0.0002 & 0.6028 & $<0.0001$ & 0.0010 \\
\multirow{2}{*}{ Nut-per-cone } & Historical & $0.1379 \pm 0.0024^{\mathrm{c}}$ & $0.1548 \pm 0.0018^{\mathrm{b}}$ & $0.1387 \pm 0.0017^{\mathrm{c}}$ & $0.1613 \pm 0.0012^{\mathrm{a}}$ \\
& Recent & $0.1133 \pm 0.0072^{\mathrm{b}}$ & $0.1604 \pm 0.0061^{\mathrm{a}}$ & $0.1073 \pm 0.0016^{\mathrm{b}}$ & $0.1532 \pm 0.0044^{\mathrm{a}}$ \\
& p-value & 0.0043 & 0.5488 & $<0.0001$ & 0.1828 \\
\multirow{2}{*}{ Kernel-per-nut } & Historical & $0.1663 \pm 0.0031^{\mathrm{c}}$ & $0.2165 \pm 0.0020^{\mathrm{b}}$ & $0.2408 \pm 0.0021^{\mathrm{a}}$ & $0.2126 \pm 0.0012^{\mathrm{b}}$ \\
& Recent & $0.1229 \pm 0.0108^{\mathrm{c}}$ & $0.1936 \pm 0.0077^{\mathrm{a}}$ & $0.1529 \pm 0.0026^{\mathrm{b}}$ & $0.1931 \pm 0.0062^{\mathrm{a}}$ \\
\hline & $p$-value & 0.0001 & 0.0305 & $<0.0001$ & 0.0020 \\
\hline
\end{tabular}

derive a series of variables characterizing nut content, yield and quality at set level (Tab. 1). Among these, the final kernel-percone yield $(\mathrm{KCY})$ is the most important variable for industry, because it will define the amount of kernels yielded per $\mathrm{kg}$ of purchased cones, and is computed as the product of the intermediate nut-per-cone yield $(\mathrm{NCY})$ and kernel-per-nut yield $(\mathrm{KCY})$, thus $\mathrm{KCY}=\mathrm{NCY} \cdot \mathrm{KNY}$.

\section{Methods}

The hypothesis of a significant recent decline in nut and kernel yield in the four studied regions was tested by looking for significant differences between periods ("historical surveys", before 2006 vs. "recent surveys", since 2012) and between years in the variable kernel-per-cone yield, as well as in the intermediates nut-percone yield and kernel-per-nut yield. In addition, we evaluated the existence of interperiod differences in the other six variables (CFW*, NPC, NP kg, WP, D\%, WK - Tab. 1) characterizing nut and kernel output and quality. Additionally, we analysed the regional consistence of the decline by testing for interregional differences in the nine variables for the two analysed periods. Analyses were done using univariate ANOVAs, carried out separately for each region or period.

In a second step, we aimed to test whether there had been temporal changes in the influence exerted over the final kernel-per-cone yield by the two intermediate yield components, nut-per-cone yield and kernel-per-nut yield. Moreover, we also looked for temporal changes in the influence of the rest of covariates over the intermediate and final kernel yields. To carry out these analyses we computed Pearson's correlation coefficient among all variables separately for each region and period. In addition, we carried out a principal component analysis (PCA) for each period and region including all nine variables.

The third group of analyses were orientated towards disentangling the potential effects of climate and a potential biotic agent over the observed decline in kernelper-cone yield and intermediate yields.
Given the well-known relationship between annual rainfall and cone weight, and the influence of the cone weight on covariates affecting kernel-per-cone yield (number of pine nuts per cone and the rate of damaged nuts), we evaluated whether these relationships have changed over time. In particular, we checked for between-period differences in the pattern of relationship between these variables largely influencing nut yield and the standardized cone fresh weight (CFW*), by means of ANOVA's computed for each region and $100-g$ class of CFW*. Detection of significant differences between periods will give us evidence of other factors, apart from climate, controlling the rate of damaged nuts and number of pine nuts per cone.

\section{Results}

Spatial and temporal differences in nut and kernel yield

Our results evidenced a significant decrease in kernel-per-cone yield (kg of kernels per $\mathrm{kg}$ of fresh cones) in three out of the four regions analysed when comparing historical (before 2006) and current series of pine nut production (since 2012 - Tab. 2). In particular, KCY has decreased significantly in the Northern Plateau (from 0.035 to 0.018 ), Catalonia (0.024 to 0.015) and, to a lesser degree, in the Central Range (0.035 to 0.029). In the case of SW Andalusia, the slight decrease in KCY (0.033 to 0.032 ) was statistically nonsignificant.

As regards the two intermediate yields (Tab. 2), decreases in the nut-per-cone yield (kg of pine nuts in shell per kg cones) were only significant in Catalonia and the Northern Plateau (from 0.140 to 0.110 , in both regions), but not in the Central Range or in SW Andalusia. In these two regions, $\mathrm{NCY}$ ranges from $0.150-0.160$, significantly larger than in the Northern Plateau and Catalonia. On the other hand, the kernelper-nut yield KNY ( $\mathrm{kg}$ of kernel per $\mathrm{kg}$ of pine nuts in shell) decreased significantly in all four analysed regions. The reduction was more drastic in the Northern Plateau (from 0.241 to 0.153 ) than in Catalonia (0.166 to 0.123) or in the Central Range and
SW Andalusia, where KNY only fell from approx. 0.210 to 0.190 in both cases. When testing interregional differences, the most notable finding is that while the Northern Plateau had been the region with the largest KNY value in the historical series, it is now only the third.

A more detailed annual analysis of the three yield variables (KCY, NCY and KNY) allowed us to identify whether the differences between periods are associated with a general trend, or rather, with extraordinary annual events. In relation to kernelper-cone yield (Fig. 2), in the Northern Plateau we observed a significant decline in all the recent surveys compared with the historical ones. In Catalonia, the three recent series are among those with lower values, although we can identify similar values in some of the historical records. In the case of the Central Range and SW Andalusia, a recent survey (2014-2015 in both cases) revealed the lowest value for the whole series, while the other three recent surveys are close to the observed values in the historical series.

As for nut-per-cone yield (Fig. S2 in Supplementary material), the recent series for both the Central Range and SW Andalusia are quite similar to the historical series, while in Catalonia we observed a clearly decreasing pattern from the historical to the recent series. In the Northern Plateau it is possible to differentiate three different groups: one with values over 0.150 , all included in surveys from the historical series, a second, with values between 0.100 and 0.135 , in both historical and recent series, and a third, including three surveys (two from historical and one from the recent series) with $\mathrm{NCY}$ values below 0.100. The value for the 2014-2015 survey is worthy of note, with a $\mathrm{NCY}$ below 0.07 , the lowest for the analysed series.

With respect to annual variability in kernel-per-nut yield, the most evident changes are detected in the Northern Plateau and Catalonia, where all the values in the recent series are significantly lower than all the years from the historical ones. In Catalonia, the historical series had shown KNY between 0.127 and 0.208 while the recent 
Fig. 2 - Interannual differences in Kernel per cone yield for each studied region. Light grey bars refers to historical series, dark grey bars to recent series. Whisker lines show standard error. Dashed line indicates average value for the period. Uppercase letter indicate differences between periods for the same region.
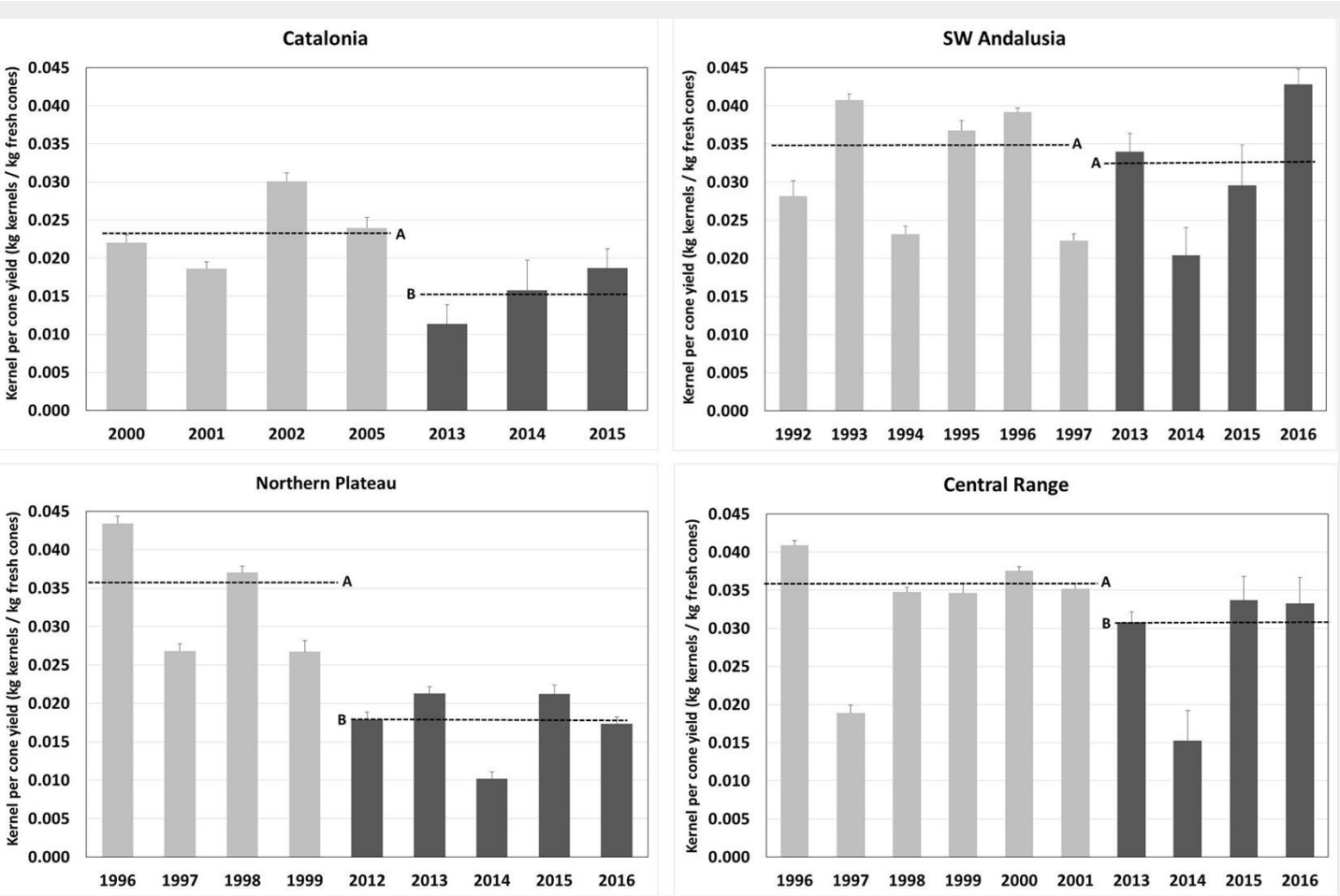

series ranges from 0.09 to 0.142 , pointing Spatial and temporal differences in the to significant decreases. In contrast, in An- covariates defining nut and kernel yield dalusia and the Central Range, the observed slight but significant decrease between periods is mainly due to the effect of the exceptionally low value found in the 2014-2015 campaign (0.159 in SW Andalusia, 0.129 in Central Range), while the rest of the recent surveys were not statistically different from the historical series (Fig. S3 in Supplementary material).
As regards the evolution of the potential covariates explaining nut and kernel yield over time, the most notable finding was the highly significant increase observed in the rate of damaged or empty pine nuts ( $D$ - Tab. 3). Apart from SW Andalusia, with an increase of $37 \%$ (from $19 \%$ to $26 \%, p=$ 0.0414 ), in the other three regions we observed a 2- to 4 -fold increment in D. The most significant increases were found in Catalonia and the Northern Plateau, where historical rates of damaged nuts were $23 \%$ and $13 \%$, whereas more recent ones reached $56 \%$ and $49 \%$, respectively. Furthermore, the rates of damaged pine nuts had never exceeded $20 \%$ (Northern Plateau) or $30 \%$ (Catalonia) for any of the years of the historical series, whilst in the recent series, the rates of damage always exceed $40 \%$ in both regions (Fig. 3). In the case of SW An-

Tab. 3 - Mean values ( \pm standard error) for nut content variables in the four regions in both historical and recent periods. P-value refers to statistical differences in the subject variable between periods for a given region. For the same row, the same lowercase indicates non-significant differences $(\mathrm{p}>0.05)$ between regions in the same period. (CFW*): standardized fresh cone weight ( $g$ ); (NPC): number of pine nuts per cone; (NP kg): number of pine nuts per kg of fresh cones; (WP): weight of a single pine nut in shell (g); (D): rate of damaged or empty pine nuts; (WK): weight of a single kernel (g).

\begin{tabular}{|c|c|c|c|c|c|}
\hline Variable & Period & Catalonia & SW Andalusia & Northern Plateau & Central Range \\
\hline \multirow{3}{*}{$\mathrm{CFW}^{*}$} & Historical & $257.8 \pm 5.0^{c}$ & $149.7 \pm 2.4^{d}$ & $269.5 \pm 3.5^{b}$ & $308.7 \pm 2.6^{a}$ \\
\hline & Recent & $261.8 \pm 12.0^{a}$ & $245.9 \pm 10.4^{\mathrm{ab}}$ & $229.1 \pm 3.0^{b}$ & $251.9 \pm 7.0^{a}$ \\
\hline & $p$-value & 0.8153 & $<0.0001$ & $<0.0001$ & $<0.0001$ \\
\hline \multirow{3}{*}{ NPC } & Historical & $65.6 \pm 1.5^{d}$ & $44.7 \pm 0.7^{c}$ & $76.1 \pm 1.1^{b}$ & $83.8 \pm 0.8^{a}$ \\
\hline & Recent & $52.9 \pm 3.6^{c}$ & $65.5 \pm 3.4^{b}$ & $55.5 \pm 1.0^{c}$ & $80.1 \pm 2.6^{a}$ \\
\hline & $p$-value & 0.0138 & $<0.0001$ & $<0.0001$ & 0.3352 \\
\hline \multirow{3}{*}{ NP_kg } & Historical & $270.4 \pm 6.2^{b}$ & $367.9 \pm 9.4^{\mathrm{a}}$ & $292.8 \pm 4.6^{b}$ & $276.0 \pm 2.5^{b}$ \\
\hline & Recent & $203.6 \pm 11.1^{c}$ & $266.7 \pm 10.1^{b}$ & $246.0 \pm 4.3^{b}$ & $328.0 \pm 12.8^{a}$ \\
\hline & $p$-value & 0.0019 & 0.0379 & $<0.0001$ & $<0.0001$ \\
\hline \multirow{3}{*}{ WP } & Historical & $0.588 \pm 0.012^{b}$ & $0.537 \pm 0.007^{c}$ & $0.509 \pm 0.005^{d}$ & $0.615 \pm 0.004^{a}$ \\
\hline & Recent & $0.575 \pm 0.031^{\mathrm{a}}$ & $0.613 \pm 0.019^{a}$ & $0.455 \pm 0.005^{b}$ & $0.486 \pm 0.013^{b}$ \\
\hline & $p$-value & 0.7642 & 0.0236 & $<0.0001$ & $<0.0001$ \\
\hline \multirow{3}{*}{ D } & Historical & $0.230 \pm 0.012^{\mathrm{a}}$ & $0.186 \pm 0.007^{b}$ & $0.134 \pm 0.007^{c}$ & $0.094 \pm 0.004^{d}$ \\
\hline & Recent & $0.560 \pm 0.045^{a}$ & $0.257 \pm 0.037^{b}$ & $0.492 \pm 0.010^{\mathrm{a}}$ & $0.285 \pm 0.024^{b}$ \\
\hline & $p$-value & $<0.0001$ & 0.0414 & $<0.0001$ & $<0.0001$ \\
\hline \multirow{3}{*}{ WK } & Historical & $0.131 \pm 0.003^{d}$ & $0.139 \pm 0.002^{c}$ & $0.145 \pm 0.002^{b}$ & $0.154 \pm 0.001^{a}$ \\
\hline & Recent & $0.186 \pm 0.005^{a}$ & $0.171 \pm 0.005^{a}$ & $0.152 \pm 0.002^{b}$ & $0.142 \pm 0.004^{b}$ \\
\hline & $p$-value & $<0.0001$ & 0.0011 & 0.0077 & 0.0194 \\
\hline
\end{tabular}




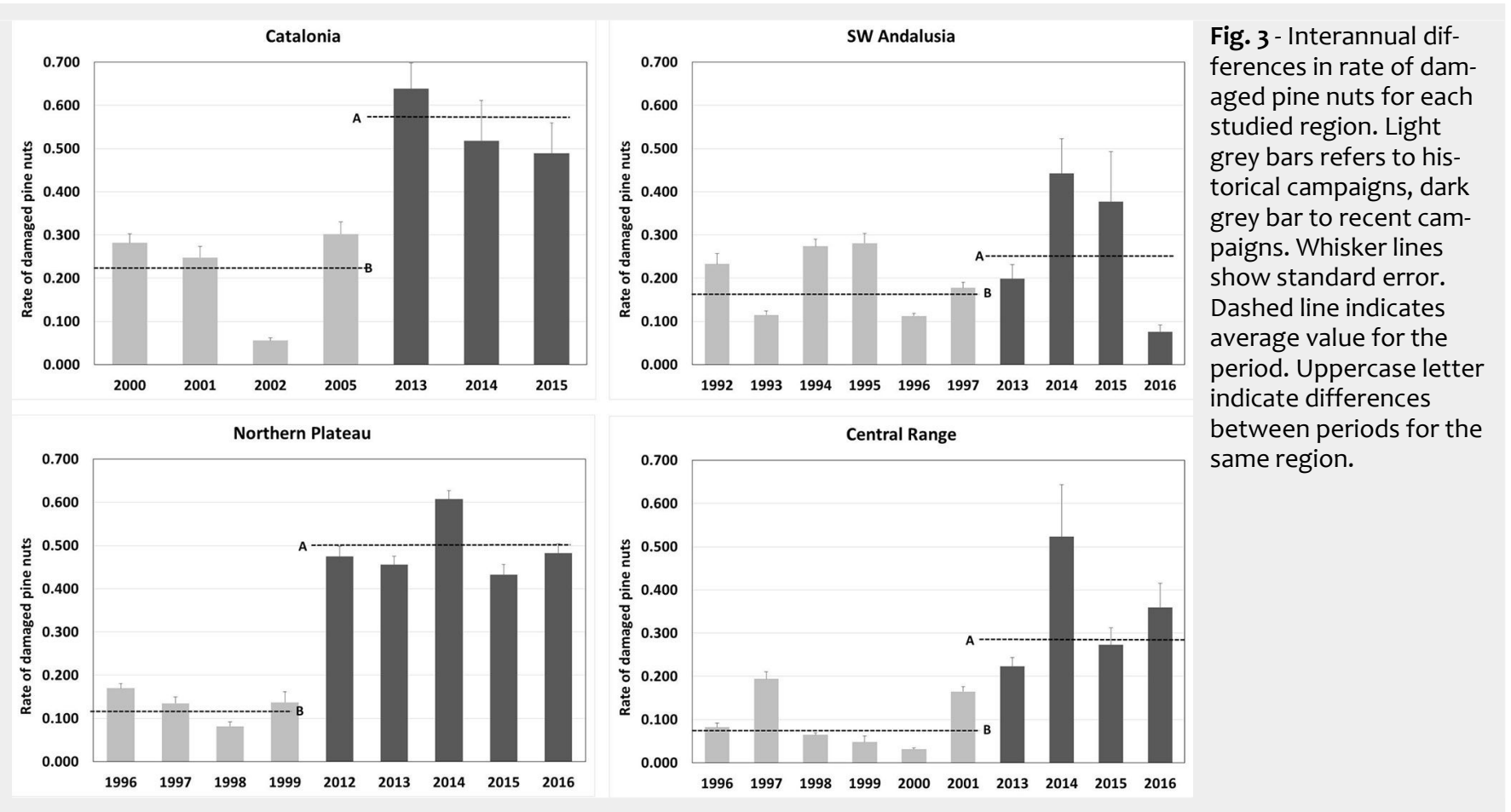

dalusia and the Central Range, the mean increment observed after 2012 is mainly due to two surveys with more than $30 \%$ damaged nuts.

As for the other covariates, the results are not consistent among regions. In Catalonia and the Northern Plateau we observed a highly significant decrease in the number of pine nuts per cone and per $\mathrm{kg}$ of fresh cones, while in the other two regions there has either been a non-significant decrease, or even a significant increase in these covariates. As an example, the number of pine nuts per cone in the Northern Plateau dropped from 76 to 55, while in the Central Range the values remain almost constantly (above a value of 80 pine nuts per cone), and in Andalusia number of pine nuts per cone has increased. The mean weight of pine nuts in shell decreased significantly after 2012 in the Northern Plateau and the Central Range, with no significant differences in Catalonia, and there was even an increase in SW Andalusia. These results are linked to similar trends observed in cone fresh weight.

Regionalised PCA confirm these patterns of shift between historical and recent series (Fig. 4 - only results for the Northern Plateau are shown). In the historical surveys, kernel-per-cone yield and nut-percone yield were highly correlated, and the number of pine nuts per cone was highly related with both, the three variables defining the first axis of variability, while the second axis was characterized by the negative correlation between the rate of damaged pine nuts with respect to kernel-pernut yield and mean weights of cones, pine nuts and kernels. In contrast, in the recent campaigns the first axis defined the close relationship between the three components of yield (NCY, KNY and KCY) and their negative relationship with respect to rate of damaged pine nuts. In this case, Euclidean distance between kernel-per-nut yield and kernel-per-cone yield is much lower than in the historical records, pointing to an increased influence of kernel-pernut yield and rate of damaged pine nuts over the final kernel-per-cone yield.

\section{Temporal shift in the correlation among} kernel-per-cone yield, intermediate yields and influential covariates

The influence of the different components of yield over final kernel-per-cone yield has varied through time in each region (Tab. 4). The most relevant finding is the generalized increase in the influence of kernel-per-nut yield over kernel-per-cone yield throughout the four studied regions. The coefficient for the correlation among $\mathrm{KNY}$ and $\mathrm{KCY}$ increases from $0.38-0.76$ in the historical series to $0.77-0.91$ in the recent series, while the coefficient for the correlation among $\mathrm{NCY}$ and $\mathrm{KCY}$, which was the highest in the historical period for all regions (except in Catalonia), varied only slightly between periods. The correlation between NCY and KNY moved from

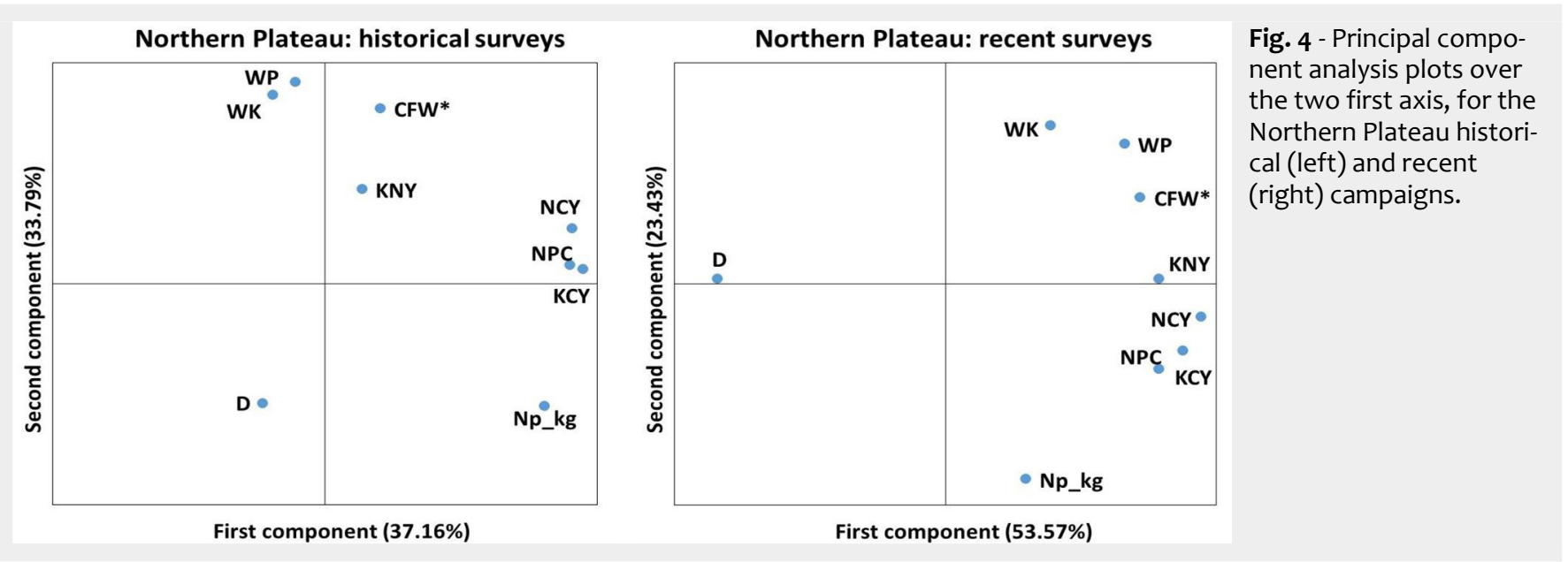


non-significant in the historical series (except in Catalonia) to significant in the recent series for all regions.

Tab. 5 shows how the influence exerted by the different analysed covariates over $\mathrm{NCY}, \mathrm{KNY}$ and $\mathrm{KCY}$ have changed over time and regions. The most consistent result is that the number of pine nuts per cone is the covariate showing the highest correlation with $\mathrm{NCY}$ in all regions and for both periods, even increasing between periods. In addition, the importance of the rate of damaged nuts, the weight of a single pine nut, and the fresh cone weight in the NCY has also substantially increased, except in the Central Range.

Concerning kernel-per-nut yield, while in historical surveys the most correlated covariate was the mean kernel weight WK, in the recent surveys the highest (negative) correlation was observed with the rate of
Tab. 4 - Correlation coefficient between the different components of yield. Values below and over the diagonal for each region represents correlation values for the his torical and recent series of nut production, respectively, for each region. $(\mathrm{NCY})$ : nutper-cone yield; (KNY): kernel-per-nut yield; $(\mathrm{KCY})$ : kernel-per-cone yield. $\left({ }^{*}\right)$ : $p \leq 0.05$; (ns): $p>0.05$.

\begin{tabular}{llccc}
\hline Region & Components & NCY & KNY & KCY \\
\hline \multirow{3}{*}{ Catalonia } & NCY & - & $0.587^{*}$ & $0.824^{*}$ \\
& KNY & $0.203^{*}$ & - & $0.909^{*}$ \\
\multirow{4}{*}{ Northern Plateau } & KCY & $0.745^{*}$ & $0.755^{*}$ & - \\
& KCY & - & $0.508^{*}$ & $0.835^{*}$ \\
& KNY & $-0.013^{\text {ns }}$ & - & $0.856^{*}$ \\
\multirow{3}{*}{ SW Andalusia } & NCY & $0.880^{*}$ & $0.409^{*}$ & - \\
& KNY & - & $0.592^{*}$ & 0.915 \\
& NCY & $-0.052^{\text {ns }}$ & - & $0.853^{*}$ \\
\multirow{3}{*}{ Central Range } & NCY & $0.736^{*}$ & $0.573^{*}$ & - \\
& KNY & - & $0.269^{*}$ & $0.797^{*}$ \\
& KCY & $-0.097^{\text {ns }}$ & - & $0.774^{*}$ \\
\hline
\end{tabular}

Tab. 5 - Temporal shift in the correlation coefficients relating nut contents covariates with the different components of nut yield at regional level. All the coefficients are significant $(\mathrm{p}<0.05)$, except those indicated by "ns". (\$): most influential covariate explaining nut-per-cone yield, kernel-per-nut yield and kernel-per-cone yield for each region and period; (CFW*): standardized fresh cone weight (g); (NPC): number of pine nuts per cone; (NP_kg): number of pine nuts per kg of fresh cones; (WP): weight of a single pine nut in shell (g); (D): rate of damaged or empty pine nuts; (WK): weight of a single kernel (g); (CAT): Catalonia; (SWA): South West Andalusia; (NP): Northern Plateau; (CR): Central Range.

\begin{tabular}{|c|c|c|c|c|c|c|c|c|c|c|c|c|c|}
\hline \multirow{2}{*}{ Param } & \multirow{2}{*}{ Kind } & \multicolumn{4}{|c|}{ Nut-per-cone yield } & \multicolumn{4}{|c|}{ Kernel-per-nut yield } & \multicolumn{4}{|c|}{ Kernel-per-cone yield } \\
\hline & & CAT & SWA & NP & CR & CAT & SWA & NP & CR & CAT & SWA & NP & CR \\
\hline \multirow{2}{*}{$\mathrm{CFW}^{*}$} & Historical & 0.476 & 0.143 & 0.267 & 0.469 & 0.448 & 0.319 & ns & ns & 0.617 & 0.341 & 0.214 & 0.424 \\
\hline & Recent & 0.596 & 0.513 & 0.557 & ns & 0.657 & 0.399 & 0.339 & 0.295 & 0.636 & 0.516 & 0.507 & ns \\
\hline \multirow{2}{*}{ Npc } & Historical & $0.695^{5}$ & $0.718^{\mathrm{s}}$ & $0.801^{\$}$ & $0.796^{5}$ & ns & ns & ns & -0.097 & 0.440 & $0.560^{s}$ & $0.723^{\$}$ & $0.698^{5}$ \\
\hline & Recent & $0.874^{5}$ & $0.782^{5}$ & $0.873^{\$}$ & $0.761^{\$}$ & 0.501 & 0.430 & 0.378 & 0.460 & 0.736 & 0.693 & 0.701 & 0.756 \\
\hline \multirow{2}{*}{ WP } & Historical & 0.378 & ns & 0.133 & 0.317 & 0.597 & 0.399 & 0.103 & ns & 0.616 & 0.262 & 0.097 & 0.190 \\
\hline & Recent & 0.581 & 0.492 & 0.483 & ns & 0.625 & 0.507 & 0.427 & ns & 0.589 & 0.569 & 0.502 & ns \\
\hline \multirow{2}{*}{ Np_kg } & Historical & 0.277 & 0.461 & 0.701 & 0.536 & -0.465 & -0.505 & ns & ns & -0.128 & ns & 0.612 & 0.512 \\
\hline & Recent & 0.562 & 0.559 & 0.574 & 0.640 & ns & ns & ns & ns & 0.385 & 0.422 & 0.346 & 0.508 \\
\hline \multirow{2}{*}{ D } & Historical & -0.486 & -0.197 & -0.206 & -0.496 & -0.704 & -0.586 & $-0.449^{\$}$ & -0.212 & $-0.711^{\text {s }}$ & -0.553 & -0.364 & -0.507 \\
\hline & Recent & -0.640 & -0.620 & -0.591 & -0.303 & $-0.969^{\$}$ & $-0.934^{s}$ & $-0.952^{\$}$ & $-0.946^{s}$ & $-0.935^{\$}$ & $-0.847^{s}$ & $-0.884^{s}$ & $-0.775^{s}$ \\
\hline \multirow{2}{*}{ WK } & Historical & 0.165 & -0.187 & -0.097 & -0.207 & $0.753^{\$}$ & $0.627^{5}$ & 0.364 & $0.541^{s}$ & 0.601 & 0.196 & 0.087 & 0.094 \\
\hline & Recent & ns & ns & 0.177 & ns & ns & ns & 0.262 & ns & 0.194 & ns & 0.241 & ns \\
\hline
\end{tabular}

Fig. 5 - Influence of cone fresh weight on rate of damaged nuts. Black lines represents modern campaigns, while grey lines represents historical campaigns. $(* * *, * *, *)$ : represents significant differences at $\mathrm{p}<$ $0.0001, p<0.01$ and $p<0.05$ respectively, between periods for a given class of cone fresh

weight. "n.s" indicates nonsignificant differences between periods for a given class of cone fresh weight.
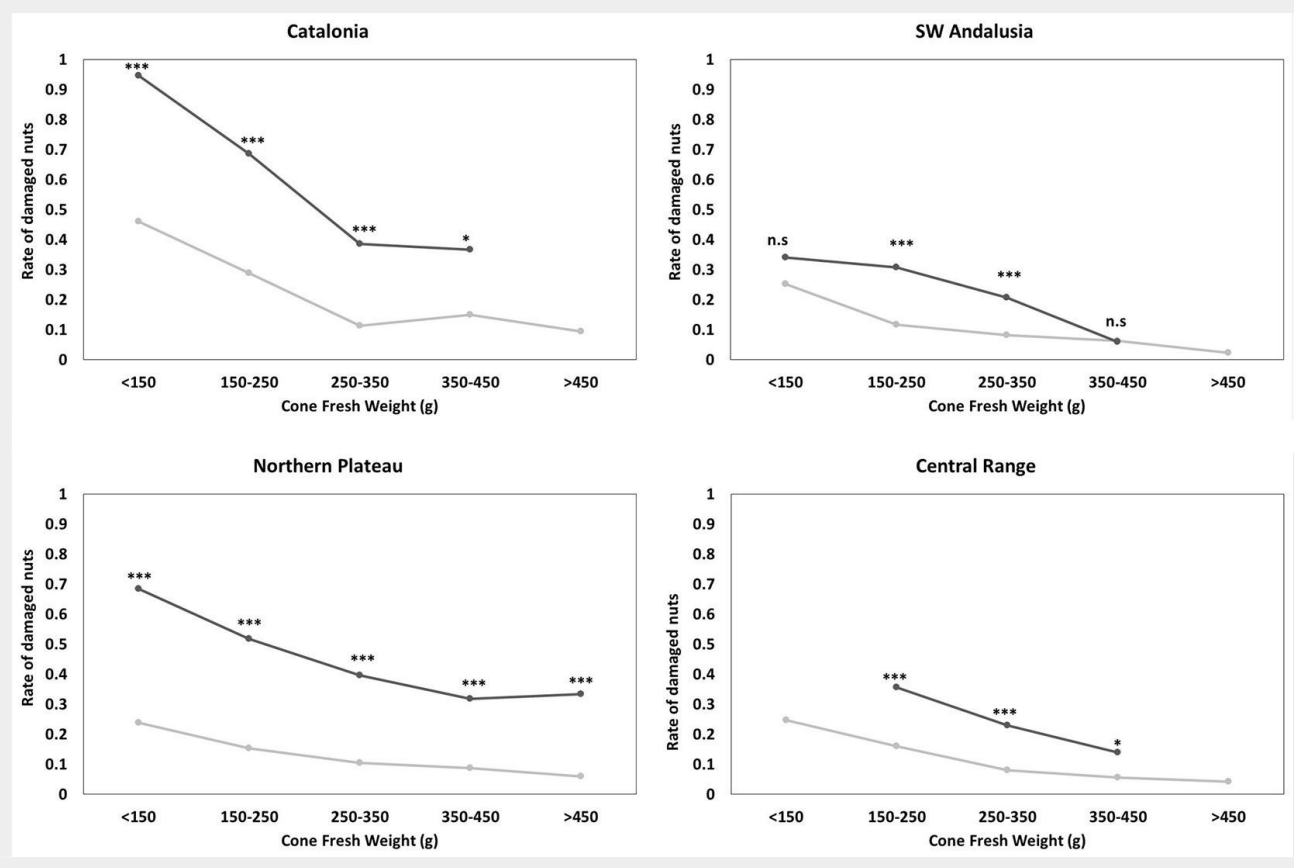
damaged nuts for all regions, while correlation between WK and KNY is no longer significant. The number of pine nuts per cone was not significantly related with KNY in historical surveys, but is currently significantly related in all studied regions.

Finally, when focusing on the final kernelper-cone yield, in historical surveys the number of pine nuts per cone was the most correlated covariate, except for Catalonia. In the recent surveys, the rate of damaged nuts is the most correlated covariate in all four regions, with correlation coefficient values ranging from -0.78 to -0.94 , the number of pine nuts per cone now being the second most correlated (correlation coefficient from 0.69 to 0.76 ).

\section{Influence of cone fresh weight on the} covariates defining nut content

We observed a significant $(p<0.05)$ and negative relationship between cone fresh weight and rate of damaged pine nuts for both periods in all the regions. Moreover, we detected wide significant differences between periods for the 100-g classes of fresh cone weight in all the regions analysed, with consistently more damaged nuts after 2012 (Fig. 5), 30-50 \% higher in Catalonia and the Northern Plateau and about 20 \% higher in SW Andalusia and Central Range.

A positive correlation between mean cone weight and the number of pine nuts per cone persisted for both periods in all regions, with significant differences between periods only in the $150-250 \mathrm{~g}$ and 250-350 $\mathrm{g}$ classes of cone weight in the Northern Plateau and in the $150-250 \mathrm{~g}$ in Catalonia (with less pine nuts per cone than before 2006 - Fig. S4 in Supplementary material).

\section{Discussion}

The results presented in this work confirm and quantify for the first time the recent and generalized decline in the kernel-per-cone yield in Pinus pinea forests throughout Spain due to a sharp increase in the rate of damaged (or empty) pine nuts. Thanks to the extensive network of monitoring points and to the availability of data on pine nut and kernel yield from two series of surveys, one prior to 2006 and the other since 2012, it has been possible to confirm a statistically significant decrease in the final kernel-per-cone yield in three out of the four analysed regions, reaching values of $50 \%$ reduction in the Northern Plateau or $33 \%$ reduction in Catalonia, resulting in current $\mathrm{KCY}$ values over 0.015 .

The observed magnitude of the decline in kernel-per-cone yield is in accordance with previous information reported for the distribution area of the species as a whole. Data from six processing industries in Portugal and Spain compiled by Mutke et al. (2017) showed a decrease in KCY from a stable 0.038 before 2008 to $0.022-0.028$. Reports from Italy (Agri-Ciencia 2014) have indicated a reduction from 0.035 to 0.005 , and severe reduction in $\mathrm{KCY}$ was also reported from Lebanon (Piqué et al. 2017) and Turkey (Parlak 2017). However, our results allow to confirm this decline at a much more detailed forest scale, over a wide variety of forests across the whole range for the species in Spain.

In addition, our findings allow to identify which of the intermediate yields is implied in the decline, providing insight into the potential causes for this reduction. In this regard, a significant decrease in nut-per-cone yield was only observed in the Northern Plateau and Catalonia, while for the kernelper-nut yield, significant reductions were observed in all four regions. Before 2006, the nut-per-cone yield was the most important component affecting kernel-per-cone yield, while kernel-per-nut yield was almost constant (Calama et al. 2007, Morales 2009). From 2012 onwards, KNY exerts a greater influence on $\mathrm{KCY}$, this being the main cause for the observed decrease in $\mathrm{KCY}$. A final point to mention is that while both components tended to be unrelated and independent prior to 2006, after 2012 a significant positive correlation was found between them for all regions, pointing to the existence of a new factor influencing both intermediate contents in a similar way.

Since 2012, the rate of damaged pine nuts has significantly increased in the four studied regions, reaching mean values over 0.50 in Catalonia and the Northern Plateau and over 0.30 in SW Andalusia and Central Range, which equates closely with the increase in damaged pine nuts reported from different regions in the Mediterranean (Mutke et al. 2017, Farinha et al. 2017). The increased presence of normal-sized, but empty or damaged pine nuts is the main cause of the observed drop in the kernelper-nut yield in Pinus pinea. Furthermore, the number of pine nuts per cone and the rate of damaged pine nuts has been correlated with the mean weight of cones (Morales 2009, Calama et al. 2007) and subsequently with the amount of rainfall during the last year of cone maturation (Mutke et al. 2007, Calama et al. 2016a, Guadaño et al. 2016); thus, we could infer a certain degree of climatic control over these two contents. However, our results show that for a given cone size, the rate of damaged pine nuts is much larger and the number of pine nuts per cone is lower in the recent surveys than in the historical ones (covering years with different climatic conditions in both periods), confirming that other factor, apart from climate, may control over the decline in kernel-per-cone yield.

Our results are in agreement with previous findings focusing on L. occidentalis (Farinha et al. 2017, 2018b, Elvira-Recuenco et al. 2016) as the main causal agent provoking the reduction in kernel-per-cone yield, based on feeding experiments in the field and laboratory-reared bugs. In addition, we have detected a higher number of seed abortions per cone (lower values of num- ber of pine nuts per cone) coinciding with the years with larger rate of damaged pine nuts at least in two of the regions (Northern Plateau and Catalonia), which is in concordance with $L$. occidentalis damage on inmature conelets reported for stone pine (Ponce et al. 2017, Farinha et al. 2018a) and other pine species (Strong et al. 2001, Lesieur et al. 2014).

However, our results do not exclude a possible second-order effect of climate, as suggested by Farinha et al. (2018a) or Elvira-Recuenco et al. (2016), who also detected a certain amount of damaged seeds in cones protected from L. occidentalis attack by means of exclusion bags. In addition, severe lack of precipitation outside the summer drought period, as occurred in the winter and spring seasons of 2017 in the Northern Plateau, resulted in very small cones (mean weight below $100 \mathrm{~g}$ ). The survey in that year (results not shown) revealed the lowest kernel-per-cone yield of the whole series (with values below 0.005), associated with the highest rates of damaged nuts (over 0.87) and the lowest number of pine nuts per cone (13), evidencing that potential biotic damage can be aggravated by extreme dry years.

While there is a generalized increase in the rate of damaged pine nuts and the subsequent reduction in the kernel-per-cone yield throughout the four studied regions, we can identify different spatiotemporal patterns. The Northern Plateau and Catalonia show quite constant rates of damaged pine nuts, clearly exceeding the records from the historical series and pointing to a degree of stabilization and persistence in the damage. In addition, both regions show significant decrease in the number of pine nuts per cone. In contrast, in SW Andalusia and the Central Range, the damage in the recent series seems to be concentrated in one or two specific surveys, showing a descending trend in recent years. While spatial differences at within-region scale in the rate of damaged pine nuts have recently been associated with different aspects such as site productivity (Farinha et al. 2018b), stand stocking (Calama et al. 2017b) or forest composition (Villaseñor 2018), it is not clear which mechanisms could regulate interregional differences. The wide phenological differences between the regions, resulting in a twomonth anticipated cone and seed maturation in SW Andalusia with respect to Northern Plateau and Catalonia (Montero et al. 2004), and the subsequent uncoupling with the lifecycle of Leptoglossus have been postulated as a possible explanation, though lacking of scientific evidences. As regards the temporal variability, higher rates of damage seem to occur in those years (e.g., 2014-2015) with lower cone production, reinforcing the hypothesis of a biotic agent provoking a higher predatory pressure in years with scarce resources. 


\section{Conclusions}

This study confirms and quantifies the existence of a generalized decline in the kernel-per-cone yield in Pinus pinea forests located in different Spanish regions. For the first time, the real magnitude of the decline has been quantified, revealing reductions of up to $50 \%$ in the final kernel-per-cone yield in the most affected regions. The observed decline in kernel-per-cone yield is mainly related to the observed increase in the rate of damaged pine nuts, and to a lesser extent, to the decrease in the number of pine nuts per cone. While both symptoms can be associated with extreme climate events our results reinforce the hypothesis of the implication of an additional biotic agent (presumably the exotic western conifer seed bug L. occidentalis). In this regard, the confirmed presence of the seed bug in the studied regions and the similitude between seed damage observed in the field and in controlled experiments support this hypothesis. However, as no efficient methods for monitoring the size of the insect population were available, it is not possible to unequivocally confirm its role as causative agent. In this regard, ongoing research into the lifecycle, feeding habits and monitoring techniques of $L$. occidentalis (Barta 2016) will permit greater insight into the causality and spatio-temporal variability of the damage.

\section{Acknowledgements}

RC, JG, SM and MP designed the study, carried the analysis and wrote the main part of the manuscript. MC, GM and EG carried out laboratory measurements and database processing. MJA, MiP, RG and GM collected and provided field data, and reviewed the manuscript.

This work has been carried out under the financial and functional framework of the PROPINEA agreement CC-16-095, between INIA, ITACYL and Deputation of Valladolid; EG-17-042-C2.2 agreement between INIA and MAPA; National Projects RTA-201300011.C2.1 and AGL-2017-83828-C2.1; and the H2020_CSA project 774632 -INCREdible. Authors wish to thank personnel from the Forest Services of Valladolid, Ávila, Junta de Andalucía and CTFC for their permanent support with the inventory, cone collection and maintenance of the experimental trials.

\section{References}

Agri-Ciencia (2014). Cadeia de valor da fileira da pinha/pinhao [Chain value for the pine nut/pine cone sector]. UNAC, Lisboa, Portugal, pp. 119. [in Portuguese]

Barta M (2016). Biology and temperature requirements of the invasive seed bug Leptoglossus occidentalis (Heteroptera: Coreidae) in Europe. Journal of Pest Science 89: 31-44. - doi: 10.1007/s10340-015-0673-z

Bates SL, Borden JH (2005). Life table for Leptoglossus occidentalis Heidemann (Heteroptera: Coreidae) and prediction of damage in lodgepole pine seed orchards. Agricultural and For- est Entomology 7: 145-151. - doi: 10.1111/j.1461-95 55.2005.00254.x

Bates SL, Strong WB, Borden JH (2002). Abortion and seed set in lodgepole and western white pine conelets following feeding by Leptoglossus occidentalis (Heteroptera: Coreidae). Environmental Entomology 31: 1023-1029. - doi: 10.1603/0046-225X-31.6.1023

Bracalini M, Benedettelli S, Croci F, Terreni P, Tiberi R, Panzavolta T (2013). Cone and seed pests of Pinus pinea: assessment and characterization of damage. Journal of Economic Entomology 106: 229-234. - doi: 10.1603/EC12293

Calama R, Mutke S, Sánchez-González M, Garriga E, Montero G (2007). Modelling spatial and temporal variability on Stone pine (Pinus pinea L.) cone quality: preliminary results. In: “EFIMED Scientific Seminar: Modelling, Valuing and Managing Mediterranean Forest Ecosystem for Non-Timber Goods and Services". Palencia (Spain) 10 Oct 2007, Oral Presentation, pp. 22. [online] URL: http://www.researchgate.net/pu blication/335723999

Calama R, Pardos M, Conde M, Madrigal G, Mutke S, Montero G, Gordo FJ (2015). Pérdidas de rendimiento en piñón en piñas de Pinus pinea L.: análisis interregional [Decline in kernel and pine nut yields in Pinus pinea L. cones: an interregional analysis]. III Reunión Científica de Sanidad Forestal SECF. Madrid (Spain) 7-8 Oct 2015. [in Spanish] [online] URL: http://www. researchgate.net/publication/282666361

Calama R, Gordo J, Madrigal G, Mutke S, Conde M, Montero G, Pardos M (2016a). Enhanced tools for predicting annual stone pine (Pinus pinea L.) cone production at tree and forest scale in Inner Spain. Forest Systems 25: e079. doi: 10.5424/fs/2016253-09671

Calama R, Gordo J, Raposo R, Elvira M, Mutke S, Pascual S, Pardos M (2016b). Pine nut damage on inmature cones of Pinus pinea L.: evidences for Leptoglossus causality. In: Proceedings of the " 2 nd International Meeting on Mediterranean Stone Pine for Agroforestry - Agropine 2016". Oeiras (Portugal) 18-20 May 2016. INIAV, Oeiras, Portugal, pp. 38-39.

Calama R, Fortin M, Pardos M, Manso R (2017a). Modelling spatiotemporal dynamics of Pinus pinea cone infestation by Dioryctria mendacella. Forest Ecology and Management 389: 136-148. doi: 10.1016/j.foreco.2016.12.015

Calama R, Gordo FJ, Mutke S, Madrigal G, Conde M, Raposo R, Elvira M, Pardos M (2017b). Variabilidad espacio-temporal en el daño asociado a Leptoglossus occidentalis en pinares de Pinus pinea de la provincia de Valladolid [Spatiotemporal variability in the damage by Leptoglossus occidentailis in Pinus pinea forests in the province of Valladolid]. In: Proceedings of the " 7 " Congreso Forestal Español". Plasencia (Spain) 26-30 Jun 2017. Sociedad Española de Ciencias Fisiológicas - SECF, Spain, pp. 482. [in Spanish] Elvira-Recuenco M, Sanchez-Moreno J, Calama R, Pardos M, Mutke S, Gordo J, Pascual S, Raposo $R$ (2016). Damage assessment in pine nuts from stone pine caused by Leptoglossus occidentalis and pathogenic agents. In: Proceedings of the Meeting "Wild Forest Products in Europe". Barcelona (Spain) 13-14 Oct 2016, Poster. [online] URL: http://www.researchgate. net/publication/309200646
Evaristo I, Batista D, Correia I, Correia P, Costa R (2010). Chemical profiling of Portuguese Pinus pinea L. nuts. Journal of the Science of Food and Agriculture 90: 1041-1049. - doi: 10.1002/js fa.3914

Farinha AO, Branco M, Pereira MFC, AugerRozenberg MA, Maurício A, Yart A, Guerreiro V, Sousa ER, Roques A (2017). Micro X-ray computed tomography suggests cooperative feeding among adult invasive bugs Leptoglossus occidentalis on mature seeds of stone pine Pinus pinea. Agriculture and Forest Entomology 20 (1): 18-27. - doi: 10.1111/afe.12225

Farinha AO, Silva JEP, Correia AC, Sousa ER, Roques A, Branco M (2018a). Is Leptoglossus occidentalis entirely responsible for the high damage observed on cones and seeds of Pinus pinea? Results from a fertirrigation trial in Portugal. Forest Ecology and Management 429: 198-206. - doi: 10.1016/j.foreco.2018.07.014

Farinha AO, Durpoix C, Valente S, Sousa E, Roques A, Branco M (2018b). The stone pine, Pinus pinea L., a new highly rewarding host for the invasive Leptoglossus occidentalis. Neobiota 41: 1-18. - doi: 10.3897/neobiota.41.30041

Fent $M$, Kment $P$ (2011). First record of the invasive western conifer seed bug Leptoglossus occidentalis (Heteroptera: Coreidae) in Turkey. North-Western Journal of Zoology 7: 72-80. [online] URL: http://biozoojournals.ro/nwjz/conten t/v7n1/nwjz.111106.Fent.pdf

Freire J, Tome M, Silva S, Ribeiro C, Teles M (2016). Silvicultural guidelines for managing $P$. pinea stands in a southeastern Portuguese region for cone production. Revised silvicultural guidelines for selected MPT and NWFPs. StarTree Deliverable 2.3, FP7 Project no 311919 KBBE 2012 (1): 2-06. European Commission, Brussels, Belgium, pp. 58-70.

Gordo J, Mutke S, Prada MA (1999). El pino piñonero (Pinus pinea L.) [The Stone pine]. In: "Mejora genética y masas productoras de semilla de los pinares españoles" (Alía R, Galera R, Martín S eds). INIA, Madrid, Spain, pp. 223239. [in Spanish]

Guadaño C, Iglesias S, Leon D, Arribas S, Gordo J, Gil L, Montero G, Mutke S (2016). Establecimiento de plantaciones clonales de Pinus pinea para la producción de piñón mediterráneo [Estabishing clonal plantations with Pinus pinea to promote pine nut production]. Monografías INIA 28, Madrid, Spain, pp. 80. [in Spanish] INC (2012). Nuts and dried fruits. Global statistical review 2007-2012. Reus, Spain, pp. 67. [online] URL: http://www.nutfruit.org/files/tech/gl ob-stat-review-2011-2012_70816.pdf

Lesieur V, Yart A, Guilbon S, Lorme P, Auger-Rozenberg MA, Roques A (2014). The invasive Leptoglossus seed bug, a threat for commercial seed crops, but for conifer diversity? Biological Invasions 16: 1833-1849. - doi: 10.1007/s10530013-0630-9

Lesieur V, Lombaertz E, Guillemaud T, Courtial B, Strong W, Roques A, Auger-Rozenberg MA (2018). The rapid spread of Leptoglossus occidentalis in Europe: a bridgehead invasion. Journal of Pest Science 92: 189-200. - doi: 10.1007/ s10340-018-0993-x

Loewe-Muñoz V, Balzarini M, Delard C, Alvarez A (2019). Variability of stone pine (Pinus pinea L.) fruit traits impacting pine nut yield. Annals of 
Forest Science 76: 37. - doi: 10.1007/s13595-0190816-0

Montero G, Candela JA, Rodríguez Navarro AC (2004). El pino piñonero (Pinus pinea L.) en Andalucía: ecología, distribución y selvicultura [Stone pine (Pinus pinea L.) in Andalusia: ecology, distribution and silviculture]. Junta de Andalucía, Sevilla, Spain, pp. 261. [in Spanish] Morales L (2009). Modelos para la predicción del contenido y calidad de piñón en piñas de Pinus pinea L. en los Valles del Tiétar y del Alberche [Empirical model for predicting pine nut content and quality in Pinus pinea $\mathrm{L}$. cones from $\mathrm{Ti}$ etar and Alberche Valleys]. MSc thesis, ETSI Montes, Universidad Politécnica de Madrid, Madrid, Spain, pp. 149. [in Spanish]

Mutke S, Gordo J, Gil L (2005). Variability of Mediterranean Stone pine cone production: yield loss as response to climate change. Agricultural and Forest Meteorology 132 (3-4): 263272. - doi: 10.1016/j.agrformet.2005.08.002

Mutke S, Iglesias S, Gil L (2007). Selección de clones de pino piñonero sobresalientes en la producción de piña [Selection of Mediterranean stone pine clones for cone production] Investigación Agraria, Sistemas y Recursos For estales 16: 39-51. [in Spanish] - doi: 10.5424/srf/ 2007161-00996

Mutke S, Calama R, Nasrallah Neaymeh E, Roques A (2017). Impact of the Dry Cone Syndrome on commercial kernel yield of stone pine cones. Options Méditerranéennes A 122: 79-84. [online] URL: http://om.ciheam.org/om/ pdf/a122/00007245.pdf

Parlak S, Kilci M, Sayman M, Akkas ME, Bucak C, Boza Z (2013). Climate factors and their relation regarding cone yield of stone pine (Pinus pinea L.) in the Kozak Basin, Turkey. Options Méditerranéennes A 105: 15-19. [online] URL: http://om. ciheam.org/om/pdf/a105/00006776.pdf

Parlak S (2017). An invasive species: Leptoglossus occidentalis (Heidemann) how does it affect forestry activities? Kastamonu University, Journal of Forestry Faculty 17 (3): 531-542. - doi: 10.17475/kastorman.292220

Ozçankaya M, Balay SN, Bucak C (2013). Effects of pests and diseases on stone pine (Pinus pinea L.) conelet losses in Kozak catchment area. Options Méditerranéennes A 105: 29-33. [online] URL: http://om.ciheam.org/om/pdf/a10 5/00006778.pdf

Pasalodos-Tato M, Pukkala T, Calama R, Cañellas I, Sánchez-González M (2016). Optimal management of Pinus pinea stands when cone and timber production are considered. European Journal of Forest Research 135: 607-619. - doi: 10.100 7/s10342-016-0958-7

Piqué $M$, Calama R, Mutke $S$, Nemer NM, Abou Daher MA, Abou-Fakhr E, Bassil M, Freiha A, Neaymeh EN, Hayek ML, Hamid AH, Sathyapala $S$ (2017). Guidelines for integrated management of sustainable pine forests. Paper no. TCP/LEB/3501, FAO/Ministry of Agriculture, Beirut, Lebanon, pp. 48. [in Arabic]

Ponce L, Ponce A, Sacristan A, Pajares JA (2017). Daños estacionales a piñas y piñones de Pinus pinea de diferentes edades causados por Leptoglossus occidentalis Heidemann (Heteroptera, Coreidae) [Stational damage in P. pinea cones and pine nuts provoked by Leptoglossus occidentalis Heidemann (Heteroptera, Coreidae)]. In: Proceedings of the " $7{ }^{\circ}$ Congreso Forestal Español”. Plasencia (Spain) 26-30 Jun 2017. Sociedad Española de Ciencias Fisiológicas - SECF, Spain, pp. 463. [in Spanish]

Prada MA, Gordo FJ, De Miguel J, Mutke S, Catalán G, Iglesias S, Gil L (1997). Regiones de procedencia de Pinus pinea [Provenance regions for Pinus pinea]. Ministerio de Medio Ambiente, Madrid, Spain, pp. 109. [in Spanish]

Salas-Salvadó J, Casas-Agustench P, Salas-Huetos A (2011). Cultural and historical aspects of Mediterranean nuts with emphasis on their attributed healthy and nutritional properties. Nutrition, Metabolism and Cardiovascular Diseases 21: 1-6. - doi: 10.1016/j.numecd.2010.10.013 Sousa E, Ferreira C, Pimpão $M$, Naves $P$, Valdiviesso T, Varela C (2012). Sanidade dos povoamentos de pinheiro manso em Portugal [Health state of Pinus pinea forests in Portugal]. In: Proceedings of the Meeting "Valorização da Fileira da Pinha/Pinhão" (Calado N ed). Alcácer do Sal (Portugal) Sept 2012. Oral presentation, pp. 36. [in Portuguese] [online] URL: http://www.unac. pt/images/eventos/seminario_valorizacao_pinh a_Edmundo_Sousa_INIAV.pdf
Strong WB, Bates SL, Stoehr MU (2001). Feeding by Leptoglossus occidentalis (Hemiptera: Coreidae) reduces seed set in lodgpole pine (Pinaceae). The Canadian Entomologist 133: 857-865. - doi: 10.4039/Ent133857-6

Tiberi R (2007). Danni alla fruttificazione del Pino Domestico: indagine sulle cause e sulle perdite di produzione [Damage to Stone pine fruiting: findings on main cause and losses ofproduction]. Technical Report, Arsia - University of Firenze - Regione Toscana, Florence, Italy, pp. 19. [in Italian]

Villaseñor D (2018). Aplicación de las TIG para la determinación de la influencia del paisaje en Leptoglossus occidentalis (Hemiptera: Coreidae) en pinares de la provincia de Valladolid [Applying GIS to determine the effect of landscape structure on Leptoglossus occidentalis (Hemiptera: Coreidae) behaviour in pinewood of Valladolid province]. MSc Thesis, Faculty of Geography, Universidad Complutense de Madrid, Madrid, Spain, pp. 61. [in Spanish]

\section{Supplementary Material}

Tab. S1 - Main ecological attributes of the four analysed regions.

Tab. S2 - Number of plots annually sampled and sets annually processed for the four regions in both historical and recent surveys.

Fig. S1 - Different typologies of damaged pine nuts and kernels.

Fig. S2 - Interannual differences in Nuts per Cone Yield for each studied region.

Fig. S3 - Interannual differences in Kernel per Nut Yield for each studied region.

Fig. S4 - Influence of cone fresh weight on number of pine nuts per cone.

Link: Calama_3180@supplo01.pdf 